in vivo $33: 1373-1379$ (2019)

doi:10.21873/invivo.11614

\title{
Post-thyroidectomy Hypocalcemia in Patients With History of Bariatric Operations: Current Evidence and Management Options
}

\author{
ELEFTHERIOS SPARTALIS ${ }^{1,2^{*}}$, ANTONIA THANASSA ${ }^{2,3^{*}}$, DIMITRIOS I. ATHANASIADIS ${ }^{4}$, \\ DIMITRIOS SCHIZAS ${ }^{2,5}$, ANTONIOS ATHANASIOU ${ }^{6}$, GEORGIOS N. ZOGRAFOS ${ }^{3}$, \\ GERASIMOS TSOUROUFLIS ${ }^{7}$, DIMITRIOS DIMITROULIS ${ }^{2,7}$ and NIKOLAOS NIKITEAS ${ }^{1,2}$ \\ ${ }^{1}$ Laboratory of Experimental Surgery and Surgical Research N.S. Christeas, \\ National and Kapodistrian University of Athens, Medical School, Athens, Greece; \\ ${ }^{2}$ Hellenic Minimally Invasive and Robotic Surgery (MIRS) Study Group, Athens, Greece; \\ ${ }^{3}$ Third Department of Surgery, Athens General Hospital "Georgios Gennimatas", Athens, Greece; \\ ${ }^{4}$ Department of Surgery, Indiana University School of Medicine, Indianapolis, IN, U.S.A.; \\ ${ }^{5} 1$ st Department of Surgery, National and Kapodistrian University of Athens Medical School, Athens, Greece; \\ ${ }^{6}$ Department of Upper GI, Bariatric \& Minimally invasive Surgery, \\ St. James' University Hospital, Leeds Teaching Hospitals NHS Trust, Leeds, U.K.; \\ ${ }^{7}$ 2nd Department of Propaedeutic Surgery, National and Kapodistrian \\ University of Athens Medical School, Athens, Greece
}

\begin{abstract}
Background/Aim: Both bariatric and thyroid surgeries promote calcium and vitamin $D$ deficiency. The correlation, however, of hypocalcemia after thyroidectomy in patients with previous bariatric surgery has been poorly described. This review aimed to investigate the relationship between history of bariatric operations and post-thyroidectomy hypocalcemia, as well as suggested management options. Materials and Methods: MEDLINE and Cochrane databases were searched for relevant publications regarding postthyroidectomy hypocalcemia in patients with previous bariatric surgery. Results: A total of 17 publications reporting on 126 patients met the inclusion criteria. These included 13 publications about Roux-en-Y gastric bypass (RYGB), 2 regarding biliopancreatic diversion (BPD), 1 about sleeve gastrectomy ( $S G)$ and 1 compared three bariatric procedures: $S G, R Y G B$, laparoscopic adjustable gastric band (LAGB).
\end{abstract}

This article is freely accessible online.

*These Authors contributed equally to the study.

Correspondence to: Eleftherios D. Spartalis MD, MSc, Ph.D., FACS, 49 Vasilissis Sofias Ave., Athens 10676, Greece. Tel: +30 6974714078, e-mail: eleftherios.spartalis@gmail.com

Key Words: Bariatric surgery, thyroidectomy, thyroid surgery, hypocalcemia, review.
Post-thyroidectomy hypocalcemia was found to be more prevalent in patients with previous $R Y G B$ and $B P D$, but not in previous LAGB and SG. Conclusion: Patients with previous bariatric surgery are at high risk of post-thyroidectomy hypocalcemia that sometimes leads to higher length of hospital stay and demands more invasive solutions. There is a need, however, for additional studies and further investigation in order to reach more conclusive results.

Obesity has become a common health problem in western countries (1) and bariatric surgery is one of the most effective therapies for these patients. This procedure reduces the metabolic risk factors in morbidly obese patients and directly results in adequate weight loss. The most popular bariatric surgeries are Roux-en-Y gastric bypass (RYGB), sleeve gastrectomy (SG), biliopancreatic diversion (BPD) and laparoscopic adjustable gastric band (LAGB) (2, 3). Sleeve gastrectomy and the adjustable gastric band are restrictive procedures while the other two are malabsorptive ones.

Although very advantageous, bariatric surgery causes vitamin and mineral deficiencies, including that of calcium and vitamin D, leading to hypocalcemia (4).

On the other hand, hypocalcemia is a common complication of thyroid surgery (5). Thus, as the number of post-gastric bypass patients increases, it is expected that an increased number of patients will be diagnosed with thyroid pathology requiring thyroid surgery. This combination of a 
post-gastric bypass patient undergoing thyroidectomy is observed to potentiate the post-operative hypocalcemia.

However, despite the growing number of bariatric procedures, there are no established management guidelines for bariatric patients after thyroidectomy. Therefore, the present review aims to investigate the relationship between previous bariatric surgery and hypocalcemia after thyroidectomy.

\section{Materials and Methods}

MedLine and Cochrane databases were searched for "bariatric surgery", "thyroid surgery", "calcium", "hypocalcemia", "low calcium" combined with the boolean operators AND/OR. The abstract list generated by the search was screened by two authors (ES and DIA). The search was limited to papers describing original patient data written in English, case reports and case-control and matched paired analyses. The final search was performed on January 27th, 2019. The results of the search and the selection process are summarized in a flow-chart (Figure 1). Out of 35 results and application of the snowball procedure, 17 publications were found to meet the criteria set and were, therefore, analyzed (Table I).

\section{Results}

Manco et al. (2004) (6) have studied 4 cases of women who had undergone a near-total thyroidectomy for multinodular goiter following a BPD procedure. In the post-operative period, patients suffered from lipid malabsorption and three of them developed symptomatic hypocalcemia treated with oral and IV administration of calcium and vitamin D. The fourth patient received IV calcium gluconate, as a preventive treatment, immediately following the procedure and for the next three days. That led to her to safe discharge without any hypocalcemia symptoms. On the other hand, one of the rest, developed severe, resistant hypocalcemia not responding to oral or IV treatment. Thus, she underwent a reoperation in order to elongate the common limb of BPD.

Rojas-Marcos et al. (2005) (7) have reported a case of a young woman who underwent BPD and three years later she was diagnosed with a suspicious thyroid nodule. Total thyroidectomy with central neck lymphadenectomy was performed without any complications, preserving at least 3 parathyroid glands. One week later, she experienced hypocalcemia related symptoms that were resistant to standard pharmaceutical supplementation. However, hypocalcemia subsided when the calcium and vitamin D doses were increased.

In a study by Pietras et al. (2008) (8), there was a case reported about a middle-aged woman with a recent history of RYGB, who had a near total thyroidectomy for a Hurthle cell adenoma. Post-operatively, she had symptoms of hypocalcemia requiring her to remain in the hospital for a week in order to receive both oral and IV calcium along with Vitamin D. Finally, a year after the discharge, the hypocalcemia persisted, and she was required to receive oral vitamin D and calcium supplementation for life.
Table I. Summary of publications.

\begin{tabular}{|c|c|c|c|c|c|}
\hline Author & $\begin{array}{l}\text { Number } \\
\text { of cases }\end{array}$ & SG & LAGB & RYGB & $\mathrm{BPD}$ \\
\hline Manco et al. (2004) & 4 & - & - & - & 4 \\
\hline Rojas-Marcos et al. (2005) & 1 & - & - & - & 1 \\
\hline Pietras et al. (2008) & 1 & - & - & 1 & - \\
\hline Durr et al. (2009) & 2 & - & - & 2 & - \\
\hline Salinger et al. (2010) & 1 & - & - & 1 & - \\
\hline McKenzie et al. (2013) & 19 & - & - & 19 & - \\
\hline Campos et al. (2014) & 2 & - & - & 2 & - \\
\hline Panazzolo et al. (2014) & 1 & - & - & 1 & - \\
\hline Gross et al. (2014) & 1 & - & - & 1 & - \\
\hline Alfonso et al. (2015) & 1 & - & - & 1 & - \\
\hline Allo Miguel et al. (2015) & 1 & - & - & 1 & - \\
\hline Baldane et al. (2016) & 1 & - & - & 1 & - \\
\hline Chereau et al. (2016) & 48 & 11 & 22 & 15 & - \\
\hline Droeser et al. (2016) & 25 & - & - & 25 & - \\
\hline Vemuri et al. (2015) & 1 & 1 & - & - & - \\
\hline Gooiz et al. (2015) & 3 & - & - & 3 & - \\
\hline Dequanter et al. (2015) & 14 & - & - & 14 & - \\
\hline Total & 126 & 12 & 22 & 87 & 5 \\
\hline
\end{tabular}

Similar results have been reported by Salinger et al. (2010) (9) regarding patient who underwent near total thyroidectomy for multi-nodular goiter 5 years after a RYGB. It was stated that the 40-year-old woman had normal pre and postoperatively values of calcium and vitamin $\mathrm{D}$ but at postoperative day 2 she presented with paresthesia and perioral numbness. Calcium was below normal, and she stayed 8 days in the hospital to receive IV calcium gluconate and vitamin D along with oral regiments to fully recover.

Panazzolo et al. (2014) (10) have presented a case of a young woman who underwent an RYGB surgery for morbid obesity. Her past surgical history included a previous right thyroid lobectomy for a benign nodule. Following bariatric surgery, she was diagnosed with a new thyroid nodule necessitating a complete thyroidectomy. In the first postoperative day, she depicted symptoms of hypocalcemia and required IV calcium, even though prior to the surgery all of her laboratory test results were normal, including that of thyroid's, vitamin D and calcium. The patient had difficulties to manage hypoparathyroidism as shown by the multiple admissions in the emergency department for hypocalcemia. As an adjuvant to the oral and IV supplementation of calcium and vitamin D, she was prescribed pancreatic lipase, which led to the normalization of both calcium, phosphorus and vitamin D levels.

An interesting case has been described by Vemuri et al. (2015) (11). A 45-year-old female with a history GS underwent a near-total thyroidectomy for a follicular neoplasm of the left thyroid lobe. In the postoperative period, even though vitamin D was normal and calcium and PTH 


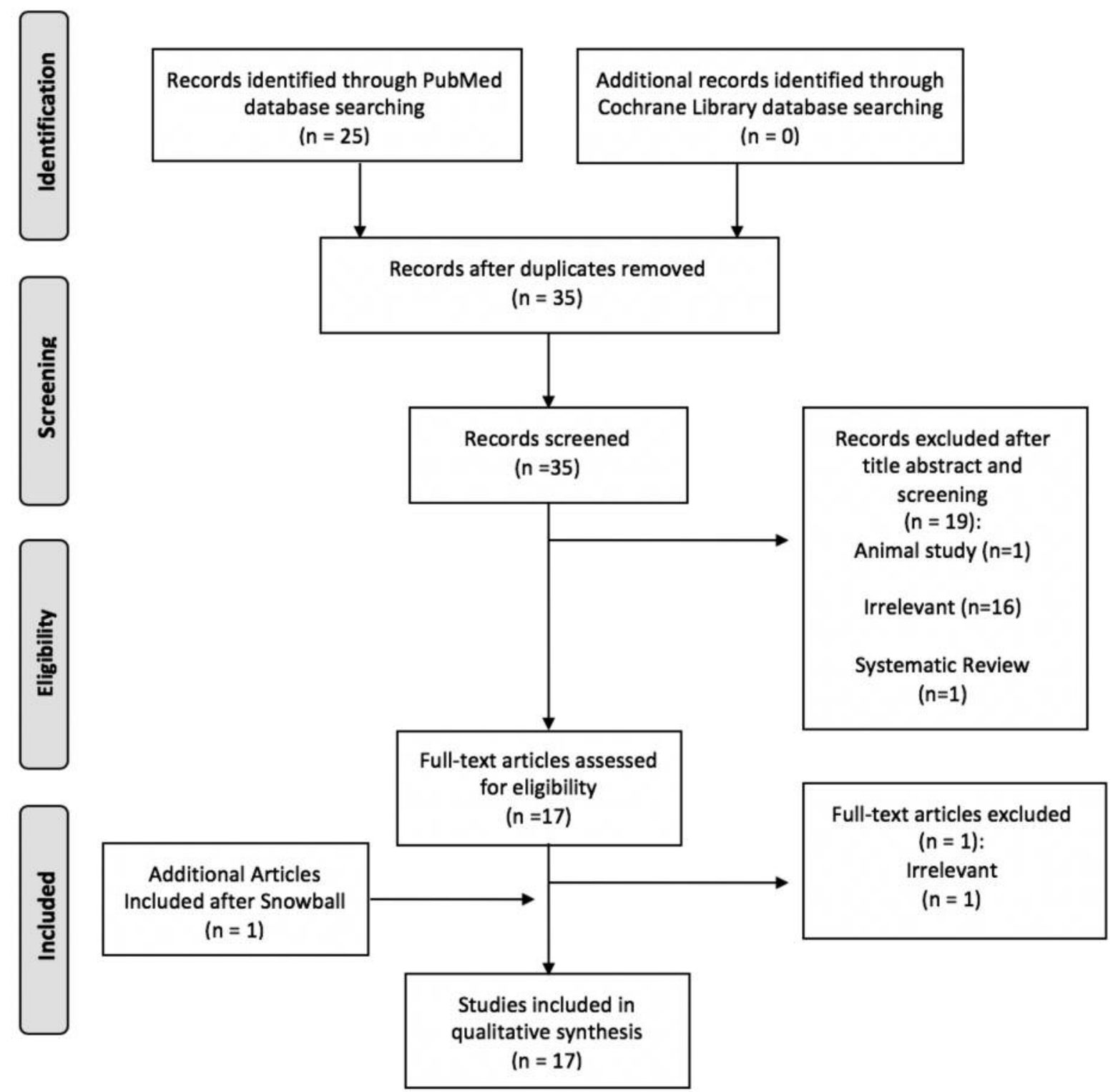

Figure 1. Flow-chart.

were in the low ends of the normal range, the patient developed symptoms of hypocalcemia requiring calcium carbonate and calcitriol. However, the symptoms persisted despite IV administration of calcium gluconate. Subsequent treatment with calcium acetate led to her discharge.

In 2016, Baldane et al. (2016) (12) similarly to Palazzolo's case, reported a case of a young female patient with resistant hypocalcemia one year after total thyroidectomy for a benign nodule. The patient had a previous history of an RYGB surgery. Despite high doses of calcium, calcitriol, ergocalciferol, and magnesium, she needed the addition of pancreatic lipase to achieve satisfying levels of calcium.

The two patients, discussed by Campos et al. (2014) (13), underwent RYGB reversal after encountering severe postoperative hypocalcemia following a thyroidectomy procedure. They were initially treated with calcium tablets, vitamin D and recombinant parathyroid hormone (rPTH) without any result. After the failure of IV administration of calcium, a gastrostomy (G-tube) was placed in order to deliver calcium and other nutrients through the excluded stomach and the duodenum. That initiative led to an 
improvement of the hypocalcemia confirming that an RYGB reversal would alleviate the symptoms.

McKenzie et al. (2013) (14), have evaluated 19 patients with previous RYGB who underwent thyroidectomy. After performing a case-matched study with 38 controls, they discovered that the 19 patients had a greater chance of acquiring symptomatic hypocalcemia ( $42 \%$ vs. $0 \%, p<0.01)$, requiring IV calcium requirement $(21 \%$ vs. $0 \%, p<0.01)$ and as a consequence, prolonged hospital stay ( 2.2 vs. 1.2 days, $p=0.02)$.

The study by Dequanter et al. (2016) (15) has included 14 patients with previous RYGB history who underwent total thyroidectomy. These patients were case-matched with 23 controls. It was revealed that patients with a history of RYGB were more prone to develop symptomatic hypocalcemia compared to controls (38\% vs. $0 \%, p<0.01)$. Moreover, the duration of hospital stay was higher (2.2 vs. 1.2 days, $p=0.02$ ). In this study, all patients developing recalcitrant hypocalcemia with a serum calcium of less than $6.5 \mathrm{mg} / \mathrm{dl}$ were treated with IV administration of calcium as adjunctive to the oral supplementation. As such, $18 \%$ of the RYGB group received IV administration of calcium compared to $0 \%$ of the control group, $p<0.01$.

Gross et al. (2014) (16) have reported a middle-aged man with a history of previous RYGB, who had undergone total thyroidectomy with central and bilateral neck dissection due to metastatic papillary carcinoma. After surgery, he had severe hypocalcemia and required aggressive oral and IV repletion therapy with calcium, magnesium, vitamin D and a thiazide diuretic, thus, normalizing the levels of calcium and PTH.

In a 2015, Alfonso et al. (17) reported on a case of a 58 years old woman who had undergone total thyroidectomy for the follicular variant of papillary thyroid carcinoma. Her history included RYGB surgery. Postoperatively, she developed severe symptomatic hypocalcemia that required large doses of calcium and vitamin D via IV and the oral route. In spite of her persistent hypoparathyroidism, she acquired a normal level of calcium.

The study by Durr et al. (2009) (18) included 2 patients with postoperative hypocalcemia after total thyroidectomy and a history of RYGB surgery. They required 12 and 16 days of IV administration of calcium, respectively.

Allo Miguel et al. (19) have reported the use of teriparatide in their patient who underwent thyroid surgery after a bariatric procedure but the response was not satisfactory and they reversed RYGB.

A different approach was followed by Gooi et al. (2014) (20) in order to address the postoperative hypocalcemia that obese patients, with such surgical history, so often develop. The three patients included in this study underwent a staged total thyroidectomy with 2-3 months interval between the two operations. The first and third patient were diagnosed with a papillary thyroid microcarcinoma (PMTC) while the second one with papillary thyroid carcinoma (PTC). The staged procedure included two operations, initially a lobectomy and isthmusectomy at the side of the PTC or PMTC followed by completion thyroidectomy three months later. At the end of the staged procedure all patients were normocalcemic, evading the not so rare side effects of hypocalcemia that are commonly observed in these patients.

A unique study, published by Chereau et al. in 2016 (21), presented patients who were operated for thyroid pathology and had undergone different types of bariatric surgery, including RYGB, SG, and LAGB. These patients were matched with patients without a history of bariatric operation. Eventually, 48 patients were reported, 19 of whom had postoperative hypocalcemia which persisted in only 5 of them. The only risk factor that was linked with hypocalcemia was found to be the type of surgery. Specifically, in RYGB procedures the risk of hypocalcemia was double than that in SG or LAGB $(60 \% v s$. $30 \%$ ). Furthermore, in a match-paired analysis, the risk of reduced levels of calcium was found to be increased in patients with previous bariatric surgery and history of thyroidectomy compared with those who did not have any thyroid surgery (40\% vs. 15\%). Likewise, the mean length of hospital stay was increased in the latter category (4.2 vs. 1.9 days, $p<0.001)$.

In contrast to the previous studies, Droeser et al. (22) have reported different results. They created a cohort study by identifying patients from the Scandinavian Quality Registry for Thyroid, Parathyroid and Adrenal Surgery (SQRTPA) and from the Swedish Obesity Surgery (SOReg). They included patients with previous obesity surgery and a subsequent total thyroidectomy over the period of 2004 to 2015 . Out of 6115 patients with total thyroidectomy, only 25 met the inclusion criteria. There was no statistically significant difference in postoperative total calcium levels between patients with or without previous RYGB following total thyroidectomy. This large population-based analysis did not confirm that the patients with previous RYGB are at higher risk of postthyroidectomy hypocalcemia.

\section{Discussion}

It is known that bariatric operations cause nutritional deficiencies and thus patients require postoperative supplementation. The most common deficiencies concern that of iron, proteins, vitamin B12, calcium, magnesium, Vitamin D and other fat-soluble vitamins (23). This is mainly the result of bypassing critical portions of the gastrointestinal tract that absorb these nutrients, along with the reduced stomach acidity as a result of these operations (24-26). Specifically, regarding calcium, the main site of absorption is in the duodenum and proximal jejunum. In a healthy adult individual, $80-100 \%$ of dietary calcium is absorbed by the duodenum via a vitamin $\mathrm{D}$ dependent transcellular active transport mechanism (27). In the case that duodenum is bypassed, calcium is absorbed by a weaker paracellular 
transport mechanism in the ileum. Biliopancreatic diversion and Roux-en-Y gastric by-pass, disrupt these mechanisms and the low gastric acidity that is formed disturb calcium absorption even further.

Moreover, the deficiency in fat-soluble vitamins, including vitamin $\mathrm{D}$, in bariatric patients is a concern. The main etiologic mechanism is the insufficient mixture of biliary salts and dietary fat. Furthermore, in obese patients, there is a primary deficiency of vitamin D due to its decreased cutaneous synthesis and intestinal absorption (28-30). Another reason is that the reduced uptake of daily calories after bariatric surgeries leads to a reduction of daily vitamin D to almost half (9). Also, most bariatric patients develop an intolerance to calcium-rich foods after surgery (31). As a consequence, obese patients are particularly susceptible to vitamin $\mathrm{D}$ and calcium deficiency $(1-3,18,32-35)$. In addition, depending on the type of bariatric operation there are different consequences on the vitamin D levels. As observed from other studies, RYGB and BPD operations, due to their nature, further decrease the intestinal absorption of vitamin $\mathrm{D}$ $(2,3,36)$ and that of calcium (21). However, there seems to be no difference in the absorption of any other nutrient between RYGB and other bariatric operations such as GS (37).

Apart from the bariatric operations, thyroidectomy is another common procedure that may cause hypocalcemia $(38,39)$. Specifically, it is the most common complication of total thyroidectomy, concerning $20 \%$ of the patients (5), with $10 \%$ of them being symptomatic (40), while permanent hypoparathyroidism is associated with hypocalcemia in about $1-3 \%$ (38). There are many known risk factors for postthyroidectomy hypocalcemia such as inadvertent excision of parathyroid glands, low preoperative vitamin D level, bilateral central lymph node neck dissection, thyroid diseases such as autoimmune Hashimoto thyroiditis and female gender $(38,39)$.

The main pathophysiology of the resulting transient hypocalcemia is the parathyroids' malfunction due to the stress inflicted by the surgical handling during the operation. On the other hand, permanent hypocalcemia most commonly occurs following a thyroid operation when the parathyroid glands are accidentally excised. The transient hypocalcemia can be minimized by prescribing calcium and/or vitamin D supplements to the patients postoperatively, which, unfortunately, does not decrease the risk of permanent hypothyroidism (41). However, the only confirmed way of predicting postoperative hypocalcemia is the reduction of serum PTH concentration occurring 4-8 hours after the procedure $(42,43)$.

In addition, even though hypocalcemia following thyroidectomy is a very common complication, its prevalence gets even higher in patients with previous bariatric surgery $(14,21)$.

In order to control refractory and symptomatic hypocalcemia following a thyroidectomy, in patients with previous bariatric surgery, it may be needed to prescribe high doses of calcium citrate and calcitriol. Calcium citrate is argued to have better absorption than calcium carbonate due to the existing low gastric acid in the stomach (27) and low calcitriol in bariatric patients. Upgrading treatment options should only be considered after giving the highest oral dose of calcium and vitamin $\mathrm{D}$, because the hypocalcemia seen in these patients often completely resolves by increasing the dose $(7,21)$. Low levels of magnesium also need to be restored because when severely depleted, they can reduce the PTH secretion $(8,16)$. In refractory cases, the second step is establishing an IV route of calcium administration and vitamin D supplementation which has very promising results $(6,8,9$, 11, 14-18) with the exception of the study by Pietras et al., which showed that the patients required permanent calcium administration at home (8). In case of failure, switching from IV administration of calcium gluconate to calcium acetate may resolve the issue (11). The next step for refractory hypocalcemia is teriparatide, a recombinant $\mathrm{PTH}$, which can be used as an alternative to vitamin $\mathrm{D}$ non-responsive hypoparathyroidism $(39,44)$. However, the results are not very specific, especially in patients with previous bariatric surgery, thus additional studies should be conducted to identify teriparatide's effectiveness in refractory hypocalcemia (44, 45). If the hypocalcemia is resistant, the addition of a thiazide diuretic such as hydrochlorothiazide may be effective due to its favorable action on calcium absorption in the distal tubule of the kidneys (35). An alternative treatment, which is specific to the hypocalcemia of those patients, is the administration of pancreatic lipase in combination with high doses of calcium, magnesium and vitamin $\mathrm{D}(10,12,44)$.

When medication therapy fails, the recalcitrant hypocalcemia can be managed with more invasive methods. As shown in one of the patients of Manco et al. (6), a sufficient treatment is the elongation of the common limb of BPD, increasing the time that nutrients are mixed with the biliopancreatic secretions leading to improved absorption.

Finally, the last resort is the reversal of the bariatric procedure. As Campos et al. have depicted in their publication (12), the initial step entails confirmation that hypocalcemia subsides upon feeding the patient through a Gtube, going through the previously excluded portion of the stomach. If it resolves, there is a higher chance the reversal to the previous anatomy to resolve the hypocalcemia. The same approach was applied by Allo Miguel et al. (19) with similar promising results. However, the most impactful solution for patients who undergo thyroidectomy with a previous bariatric surgery is to avoid this complication from the beginning. As has been shown by Gooi et al. (20), performing a staged thyroidectomy on very high-risk patients can help avoid the almost unavoidable recalcitrant hypocalcemia. Moreover, another preventive measure is to replete calcium via IV administration of calcium gluconate as seen at one of the patients of Manco et al. (6), avoiding postoperative hypocalcemia. 


\section{Conclusion}

Bariatric surgery is an independent risk factor for postthyroidectomy hypocalcemia. This adverse event is more commonly seen in RYGB and BPD. Initially, the reduced calcium can increase the length of stay at the hospital and require patients more invasive treatment options. In more severe cases, it can lead to permanent hypocalcemia with concomitant secondary hyperparathyroidism further increasing the morbidity of these patients. Thus, ways to decrease the hypocalcemia risk, such as treatment with calcium and vitamin D prior to the procedure or performing a staged thyroidectomy seems to have promising results. However, additional studies are needed to further confirm this argument.

\section{Conflicts of Interest}

The Authors declare no conflicts of interest regarding this study.

\section{Authors' Contributions}

Drafting of the manuscript: Thanassa A, Athanasiadis DI, Spartalis E; Literature search and analysis: Athanasiadis DI, Thanassa A; Data extraction and quality assessment: Athanasiadis DI; Table drafting: Athanasiadis A, Thanassa A, Athanasiou A; Manuscript editing: Athanasiadis DI, Tsourouflis G, Dimitroulis D; Critical revision of the manuscript for important intellectual content: Spartalis E, Schizas D, Zografos G; Supervising professor: Nikiteas NI.

\section{References}

1 Slater GH, Ren CJ, Siegel N, Williams T, Barr D, Wolfe B, Dolan K and Fielding GA: Serum fat-soluble vitamin deficiency and abnormal calcium metabolism after malabsorptive bariatric surgery. J Gastrointest Surg 8(1): 48-55, 2004. PMID: 14746835.

2 Karefylakis C, Näslund I, Edholm D, Sundbom M, Karlsson FA and Rask E: Vitamin D status 10 years after primary gastric bypass: gravely high prevalence of hypovitaminosis $\mathrm{D}$ and raised PTH levels. Obes Surg 24(3): 343-348, 2014. PMID: 24163201. DOI: $10.1007 / \mathrm{s} 11695-013-1104-\mathrm{y}$

3 Bloomberg RD, Fleishman A, Nalle JE, Herron DM and Kini S: Nutritional deficiencies following bariatric surgery: What have we learned? Obes Surg 15(2): 145-154, 2005. PMID: 15802055. DOI: $10.1381 / 0960892053268264$

4 Lespessailles E and Toumi H: Vitamin D alteration associated with obesity and bariatric surgery. Exp Biol Med 242(10): 1086-1094, 2017. PMID: 28103699. DOI: 10.1177/15353702166 88567

5 Hundahl SA, Cady B, Cunningham MP, Mazzaferri E, McKee RF, Rosai J, Shah JP, Fremgen AM, Stewart AK and Hölzer S: Initial results from a prospective cohort study of 5583 cases of thyroid carcinoma treated in the United States during 1996: An American college of surgeons commission on cancer patient care evaluation study. Cancer 89(1): 202-217, 2000. PMID: 10897019.

6 Manco M, Nanni G, Tondolo V, Iaconelli A, Greco AV, Castagneto $\mathrm{M}$ and Mingrone G: Hypocalcemia complicating near-total thyroidectomy in patients with coexisting lipid malabsorption due to biliopancreatic diversion. Obes Surg 4(10): 1429-1434, 2004. PMID: 15603666. DOI: 10.1381/0960892042 583752

7 Rojas-Marcos PM, Rubio MA, Kreskshi WI, Cabrerizo L and Sanchez-Pernaute A: Severe hypocalcemia following total thyroidectomy after biliopancreatic diversion. Obes Surg 15(3): 431-434, 2005. PMID: 15826482.

8 Pietras SM and Holick MF: Refractory hypocalcemia following near-total thyroidectomy in a patient with a prior roux-en-y gastric bypass. Obes Surg 19(4): 524-526, 2009. PMID: 18592328. DOI: $10.1007 / \mathrm{s} 11695-008-9614-8$

9 Salinger EM and Moore JT: Profound hypocalcemia after neartotal thyroidectomy in a Roux-en-Y gastric bypass patient. Am Surg 76(4): E7-8, 2010. PMID: 21457633.

10 Panazzolo DG, Braga TG, Bergamim A, Pires B, Almeida H and Kraemer-Aguiar LG: Hypoparathyroidism after Roux-en-Y gastric bypass - A challenge for clinical management: A case report. J Med Case Rep 8: 357, 2014. PMID: 25348653. DOI: 10.1186/1752-1947-8-357

11 Vemuri SR, Koganti SB, Mukerji A, Razi S and Shah A GB: Recalcitrant hypocalcemia after thyroidectomy in patients post sleeve gastrectomy - challenges in management. Am Surg 81(12): E426-427, 2015. PMID: 26736152.

12 Baldane S, Ipekci SH and Kebapcilar L: Pancrelipase treatment in a patient with the history of Roux-en-Y gastric bypass operation that developed resistant hypocalcemia secondary to total thyroidectomy. Endocr Regul 50(1): 27-31, 2016. PMID: 27560634. DOI: 10.1515/enr-2016-0006

13 Campos GM, Ziemelis M, Paparodis R, Ahmed M and Belt Davis D: Laparoscopic reversal of Roux-en-Y gastric bypass: Technique and utility for treatment of endocrine complications. Surg Obes Relat Dis 10: 36-43, 2014. PMID: 24120983. DOI: 10.1016/j.soard.2013.05.012

14 McKenzie TJ, Chen Y, Hodin RA, Shikora SA, Hutter MM, Gaz RD, Moore FD and Lubitz CC: Recalcitrant hypocalcemia after thyroidectomy in patients with previous Roux-en-Y gastric bypass. Surg (United States) 154(6): 1300-1306, 2013. PMID: 23978591. DOI: 10.1016/j.surg.2013.04.031

15 Dequanter D, Shahla M, Deniz Y, Aubert C and Lothaire P: Recalcitrant hypocalcemia after total thyroidectomy and bariatric surgery. B-ENT 12: 207-209, 2016. PMID: 29727125.

16 Gross J, Olsen SM, Koch CA and Moore E: Severe symptomatic hypocalcemia following total thyroidectomy and Roux-en-Y gastric bypass. In: Laryngoscope 93(1): E6-E11, 2010. PMID: 24452904.

17 Alfonso B, Jacobson AS, Alon EE and Via MA: Previous gastric bypass surgery complicating total thyroidectomy. Ear Nose Throat J 94(3): E12-6, 2015. PMID: 25738720.

18 Durr ML, Saunders JR, Califano JA, Tufano RP, Koch WM and Ha PK: Severe hypocalcemia complicating thyroid surgery after Roux-en-Y gastric bypass procedure. Arch Otolaryngol - Head Neck Surg 135(5): 507-510, 2009. PMID: 19451473. DOI: 10.1001/archoto.2009.20

19 Allo Miguel G, García Fernández E, Martínez Díaz-Guerra G, Valero Zanuy MÁ, Pérez Zapata A, de la Cruz Vigo F and Hawkins Carranza F: Recalcitrant hypocalcaemia in a patient with post-thyroidectomy hypoparathyroidism and Roux-en-Y gastric bypass. Obes Res Clin Pract 10(3): 344-347, 2016. PMID: 26387060. DOI: 10.1016/j.orcp.2015.09.001

20 Gooi Z, Ward BK, Mener DJ, Ozgursoy OB and Pai SI: A staged thyroidectomy approach for gastric bypass patients. Laryngoscope 125: 1028-1030, 2015. PMID: 25043176. DOI: 10.1002/lary.24835 
21 Chereau N, Vuillermet C, Tilly C, Buffet C, Trésallet C, du Montcel ST and Menegaux F: Hypocalcemia after thyroidectomy in patients with a history of bariatric surgery. Surg Obes Relat Dis 13(3): 484-490, 2017. PMID: 27816436 DOI: $10.1016 /$ j.soard.2016.09.026

22 Droeser RA, Ottosson J, Muth A, Hultin H, Lindwall-Åhlander $\mathrm{K}$, Bergenfelz A and Almquist M: Hypoparathyroidism after total thyroidectomy in patients with previous gastric bypass Langenbeck's Arch Surg 402(2): 273-280, 2017. PMID: 27783 154. DOI: $10.1007 / \mathrm{s} 00423-016-1517-x$

23 Gletsu-Miller $\mathrm{N}$ and Wright BN: Mineral malnutrition following bariatric surgery. Adv Nutr An Int Rev J 4(5): 506-517, 2013. PMID: 24038242. DOI: 10.3945/an.113.004341

24 Majumder S, Soriano J, Louie Cruz A and Dasanu CA: Vitamin B12 deficiency in patients undergoing bariatric surgery: Preventive strategies and key recommendations. Surg Obes Relat Dis 9(6): 1013-1019, 2013. PMID: 24091055. DOI: 10.1016/ j.soard.2013.04.017

25 Behrns KE, Smith CD and Sarr MG: Prospective evaluation of gastric acid secretion and cobalamin absorption following gastric bypass for clinically severe obesity. Dig Dis Sci 39(2): 315-320, 1994. PMID: 8313814

26 Sax HC, Smith DC, Herkes SB and Behrns KE: Gastric acid secretion and Vitamin B 12 absorption after vertical Ronx-en-Y gastric bypass for morbid obesity. J Parenter Enter Nutr 218(1): 91-96, 1994. PMID: 8328834.

27 Johnson JM, Maher JW, DeMaria EJ, Downs RW, Wolfe LG and Kellum JM: The long-term effects of gastric bypass on vitamin D metabolism. Ann Surg 243(5): 701-704, 2006. PMID: 16633006. DOI: 10.1097/01.sla.0000216773.47825.c1

28 Buffington C, Walker B, Cowan GSM and Scruggs D: Vitamin D Deficiency in the Morbidly Obese. Obes Surg Incl Laparosc Allied Care 3(4): 421-424, 1993. PMID: 10757956. DOI: $10.1381 / 096089293765559142$

29 Aasheim ET, Hofs $\varnothing$ D, Hjelmesœth J, Birkeland KI and Bøhmer T: Vitamin status in morbidly obese patients: A cross-sectional study. Am J Clin Nutr 87(2): 362-369, 2008. PMID: 18258626. DOI: $10.1093 / \mathrm{ajcn} / 87.2 .362$

30 Bell NH, Epstein S, Greene A, Shary J, Oexmann MJ and Shaw $\mathrm{S}$ : Evidence for alteration of the vitamin D-endocrine system in obese subjects. J Clin Invest 76(1): 370-373, 1985. PMID: 2991340. DOI: $10.1172 / \mathrm{JCI} 111971$

31 Nguyen NT, Masoomi H, Magno CP, Nguyen XMT, Laugenour $\mathrm{K}$ and Lane J: Trends in use of bariatric surgery, 2003-2008. J Am Coll Surg 213(2): 261-266 2011. PMID: 21624841. DOI: 10.1016/j.jamcollsurg.2011.04.030

32 Carlin AM, Rao DS, Meslemani AM, Genaw JA, Parikh NJ, Levy S, Bhan A and Talpos GB: Prevalence of vitamin D depletion among morbidly obese patients seeking gastric bypass surgery. Surg Obes Relat Dis 2(2): 98-103, 2006. PMID: 16925330. DOI: 10.1016/j.soard.2005.12.001

33 Lin Y, Ross HL, Raeburn CD, Dewitt PE, Albuja-Cruz M, Jones EL and McIntyre RC: Vitamin D deficiency does not increase the rate of postoperative hypocalcemia after thyroidectomy. Am J Surg 204(6): 888-893, 2012. PMID: 23231931. DOI: 10.1016/ j.amjsurg.2012.10.001

34 Flegal KM, Kruszon-Moran D, Carroll MD, Fryar CD and Ogden CL: Trends in obesity among adults in the United States, 2005 to 2014. JAMA - J Am Med Assoc 315(21): 2284-2291, 2016. PMID: 27272580. DOI: 10.1001/jama.2016.6458
35 Testa A, Fant V, De Rosa A, Fiore GF, Grieco V, Castaldi P, Persiani R, Rausei S, D'ugo D and De Rosa G: Calcitriol plus hydrochlorothiazide prevents transient post-thyroidectomy hypocalcemia. Horm Metab Res 38(12): 821-826, 2006. PMID: 17163358. DOI: $10.1055 / \mathrm{s}-2006-956504$

36 Di Ciaula A, Garruti G, Baccetto RL, Molina-Molina E, Bonfrate L, Wang DQH and Portincasa P: Bile acid physiology. Ann Hepatol 16(Suppl. 1: s3-105): s4-s14, 2017. PMID: 29080336. DOI: 10.5604/01.3001.0010.5493

37 Moizé V, Andreu A, Flores L, Torres F, Ibarzabal A, Delgado S, Lacy A, Rodriguez L and Vidal J: Long-term dietary intake and nutritional deficiencies following sleeve gastrectomy or roux-eny gastric bypass in a mediterranean population. J Acad Nutr Diet 13(3): 400-410, 2013. PMID: 23438491. DOI: 10.1016/ j.jand.2012.11.013

38 Seo GH, Chai YJ, Choi HJ and Lee KE: Incidence of permanent hypocalcaemia after total thyroidectomy with or without central neck dissection for thyroid carcinoma: a nationwide claim study. Clin Endocrinol (Oxf) 85(3): 483-487, 2016. PMID: 27063793. DOI: $10.1111 /$ cen.13082

39 Edafe O, Antakia R, Laskar N, Uttley L and Balasubramanian SP: Systematic review and meta-analysis of predictors of postthyroidectomy hypocalcaemia. Br J Surg 101(4): 307-320, 2014. PMID: 24402815. DOI: 10.1002/bjs.9384

40 Cayo AK, Yen TWF, Misustin SM, Wall K, Wilson SD, Evans DB and Wang TS: Predicting the need for calcium and calcitriol supplementation after total thyroidectomy: Results of a prospective, randomized study. Surg (United States) 152(6): 10591067, 2012. PMID: 23068088. DOI: 10.1016/j.surg.2012.08.030

41 Antakia R, Edafe O, Uttley L and Balasubramanian SP: Effectiveness of preventative and other surgical measures on hypocalcemia following bilateral thyroid surgery: a systematic review and meta-analysis. Thyroid 25(1): 95-106, 2015. PMID: 25203484. DOI: $10.1089 /$ thy.2014.0101

42 Lombardi CP, Raffaelli M, Princi P, Santini S, Boscherini M, De Crea C, Traini E, D\&apos;Amore AM, Carrozza C, Zuppi C and Bellantone R: Early prediction of postthyroidectomy hypocalcemia by one single iPTH measurement. Surgery 136(6): 1236-1241, 2004. PMID: 15657581. DOI: 10.1016/j.surg. 2004.06.053

43 Grodski S and Serpell J: Evidence for the role of perioperative PTH measurement after total thyroidectomy as a predictor of hypocalcemia. World J Surg 32(7): 1367-1373, 2008. PMID: 18340480. DOI: $10.1007 / \mathrm{s} 00268-008-9545-5$

44 Bilezikian JP, Khan A, Potts JT, Brandi ML, Clarke BL, Shoback D, Jüppner H, D’Amour P, Fox J, Rejnmark L, Mosekilde L, Rubin MR, Dempster D, Gafni R, Collins MT, Sliney J and Sanders J: Hypoparathyroidism in the adult: Epidemiology, diagnosis, pathophysiology, target-organ involvement, treatment, and challenges for future research. J Bone Miner Res 26(10): 2317-2337, 2011. PMID: 21812031. DOI: 10.1002/jbmr.483

45 Díaz-Soto G, Mora-Porta M, Nicolau J, Perea V, Halperin I and Puig-Domingo M: Efficacy and safety of long term treatment of unresponsive hypoparathyroidism using multipulse subcutaneous infusion of teriparatide. Horm Metab Res 44(9): 708-710, 2012. PMID: 22473758. DOI: 10.1055/s-0032-1308971

Received April 9, 2019

Revised June 8, 2019

Accepted June 10, 2019 